\section{Discontinuation of Etanercept After Successful Treatment in Patients with Juvenile Idiopathic Arthritis}

To the Editor:

Etanercept (ETN) has been used to treat patients with juvenile idiopathic arthritis (JIA) with demonstrated efficacy and safety ${ }^{1,2}$. However, few studies have addressed the appropriate time and the way to discontinue the drug once the disease is inactive. We analyzed the progress of patients with JIA after discontinuation of ETN and the clinical response to reintroduction of the drug in those who relapsed.

A retrospective chart review 2004 to 2009 revealed that therapy with ETN had been discontinued in 26 patients with JIA due to inactive disease (16 female, 10 male). The mean age at discontinuation of drug was $11 \pm 2$ (range 2.6-18.8) years. The clinical subtypes of JIA were 11 cases of enthesitis-related arthritis, 7 rheumatoid factor-negative polyarthritis, 2 systemic JIA with polyarticular involvement, 1 psoriatic arthritis, and 1 persistent oligoarticular arthritis. Inactive disease was defined according to the criteria of Wallace, $e t a l^{3}$, which required no joints with active arthritis, no fever or other clinical signs attributable to JIA, no active uveitis, normal erythrocyte sedimentation rate or C-reactive protein concentration, and no disease activity on the physician's global assessment.

For the purposes of the study, before considering the disease inactive we also required a 3-month period since the last dose of oral or intraarticular steroids was administered. All patients were examined at least every 2 months. They were considered to have a relapse when active arthritis was detected on the physical examination. In 14 patients the withdrawal of drug was performed abruptly, and in 12 in a progressive way, either by reducing the dose or by increasing the interval between doses. Given that the disease remained inactive during the tapering process the date of discontinuation considered for analysis was the day the drug was completely stopped. ETN was restarted on all patients who relapsed.

Remission time was evaluated according to the Kaplan-Meier survival curve; comparison of qualitative data was done using the log-rank test; and the association between quantitative variables was analyzed using a Cox regression model.

The mean duration of therapy with ETN was $19 \pm 8.4$ (range 9.6-38.5) months. The disease persisted at an inactive stage for a mean $14.7 \pm 8.6$ (range 1-36) months before ETN was interrupted. In total, 24 patients had inactive disease for more than 6 months, thus meeting the criteria for clinical remission on medication ${ }^{3}$. Eighteen cases $(69 \%)$ relapsed at a mean 5.8 \pm 5.3 (0.6-15.9) months after drug discontinuation, whereas in the other 8 $(31 \%)$ patients the disease remained inactive for a mean of $21 \pm 14.7$ (range 5-44.5) months. After withdrawal of ETN the disease remained inactive in 9 children for at least 12 months, reaching the definition of clinical remission off medication ${ }^{3} ; 4$ of them relapsed between 1.5 and 4 months later and 5 continued in remission a mean $17 \pm 13$ (range 1.1-32.5) months until the end of the study.

The survival curve (Figure 1) shows that $50 \%$ of the patients continued to have inactive disease at 6 months and $39 \%$ at 12 months after drug discontinuation. No significant differences were observed in the time to relapse between the group in whom the drug was tapered and the group in whom ETN was discontinued abruptly (11 vs 14 months, respectively; $p=$ 0.48). Similarly, no association was found between the duration of inactive disease prior to drug withdrawal and the time to relapse $(\mathrm{p}=0.23)$. Due to the small sample size, differences between the clinical subtypes could not be evaluated. Patients who relapsed were started again on ETN and all responded satisfactorily, although 6 of the 18 cases received intraarticular or small and transient doses of oral steroids.

It can be concluded that the majority of patients (69\%) relapsed after discontinuation of ETN, the probability of remaining symptom-free at 6 months was $50 \%$, and the response to reintroduction of treatment was satisfactory. Unlike the results of Prince, et al in 19 patients with JIA ${ }^{4}$, the period of remission after discontinuation of ETN in patients was associated neither with the duration of inactive disease before the withdrawal nor with the method used (tapering vs abrupt cessation). Some studies on

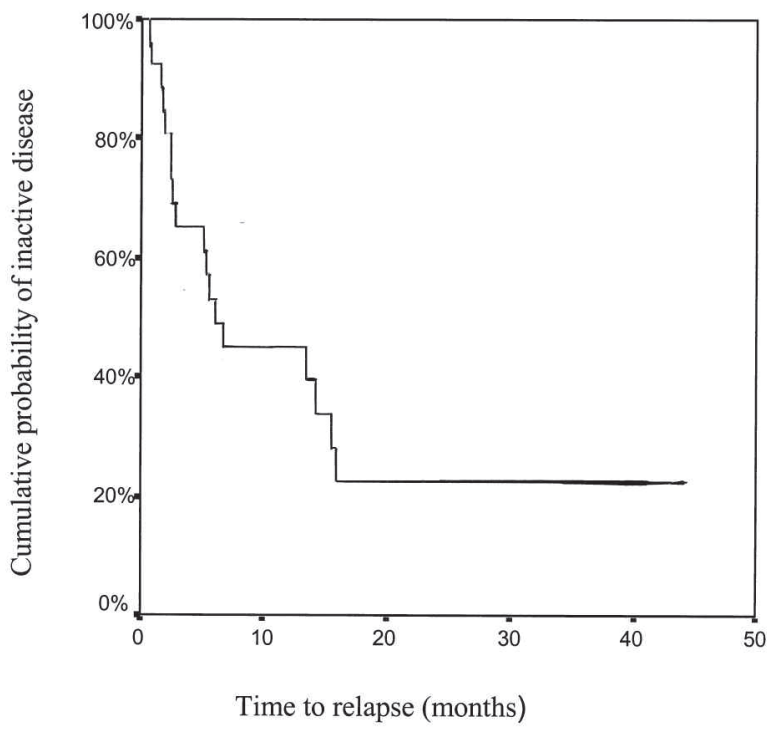

Figure 1. Cumulative probability of maintaining inactive disease after discontinuation of etanercept treatment in 26 patients with JIA.

adults with rheumatoid arthritis ${ }^{5,6}$ or ankylosing spondylitis ${ }^{7,8,9,10}$ have also shown a high incidence of relapse after discontinuation of anti-tumor necrosis factor drugs and a good response upon their reintroduction.

The 12 patients in whom the drug was reduced progressively did not relapse until its complete withdrawal, which suggests that low doses of ETN may be sufficient to maintain remission. In our opinion ETN can be discontinued after an as-yet undetermined period of disease inactivity, given that even if there is a relapse of disease patients will respond to its reintroduction.

AGUSTIN REMESAL, MD; JAIME DE INOCENCIO, MD, PhD; ROSA MERINO, MD, PhD; JULIA GARCIA-CONSUEGRA, MD, PhD, Pediatric Rheumatology Unit, Universitary La Paz Hospital, P. Castellana 261, Madrid, 28046, Spain. Address correspondence to Dr. Remesal; E-mail: agusremesal@hotmail.com

\section{REFERENCES}

1. Lovell DJ, Reiff A, Jones OY, Schneider R, Nocton J, Stein LD, et al; Pediatric Rheumatology Collaborative Study Group. Long-term safety and efficacy of etanercept in children with polyarticular-course juvenile rheumatoid arthritis. Arthritis Rheum 2006;54:1987-94

2. Giannini EH, Ilowite NT, Lovell DJ, Wallace CA, Rabinovich CE, Reiff A, et al; Pediatric Rheumatology Collaborative Study Group. Long-term safety and effectiveness of etanercept in children with selected categories of juvenile idiopathic arthritis. Arthritis Rheum 2009;60:2794-804.

3. Wallace CA, Ruperto N, Giannini E; Childhood Arthritis and Rheumatology Research Alliance; Pediatric Rheumatology International Trials Organization; Pediatric Rheumatology Collaborative Study Group. Preliminary criteria for clinical remission for select categories of juvenile idiopathic arthritis. J Rheumatol 2004;31:2290-4.

4. Prince FH, Twilt M, Simon SC, van Rossum MA, Armbrust W, Hoppenreijs EP, et al. When and how to stop etanercept after successful treatment of patients with juvenile idiopathic arthritis. Ann Rheum Dis 2009;68:1228-9.

5. Miyamura T, Sonomoto K, Nakamura M, Horai Y, Takahama S, Ando $\mathrm{H}$, et al. Discontinuation of etanercept in patients with rheumatoid arthritis who were in clinical remission. Clin 
Rheumatol 2010;29:87-90.

6. Brocq O, Millasseau E, Albert C, Grisot C, Flory P, Roux CH, et al. Effect of discontinuing TNF alpha antagonist therapy in patients with remission of rheumatoid arthritis. Joint Bone Spine 2009;76:350-5.

7. Baraliakos X, Listing J, Brandt J, Zink A, Alten R, Burmester G, et al. Clinical response to discontinuation of anti-TNF therapy in patients with ankylosing spondylitis after 3 years of continuous treatment with infliximab. Arthritis Res Ther 2005;7:R439-44.

8. Baraliakos X, Listing J, Rudwaleit M, Brandt J, Alten R, Burmester $\mathrm{G}$, et al. Safety and efficacy of readministration of infliximab after longterm continuous therapy and withdrawal in patients with ankylosing spondylitis. J Rheumatol 2007;34:510-5.

9. Brandt J, Khariouzov A, Listing J, Haibel H, Sörensen H, Grassnickel L, et al. Six-month results of a double-blind, placebo-controlled trial of etanercept treatment in patients with active ankylosing spondylitis. Arthritis Rheum 2003;48:1667-75.

10. Brandt J, Listing J, Haibel H, Sörensen H, Schwebig A, Rudwaleit $\mathrm{M}$, et al. Long-term efficacy and safety of etanercept after readministration in patients with active ankylosing spondylitis. Rheumatology 2005;44:342-8.

J Rheumatol 2010;37:9; doi:10.3899/jrheum.100219 